Research Article

\title{
Experimental Study on Bond Performance and Damage Detection of Corroded Reinforced Concrete Specimens
}

\author{
Yubin Tian $\mathbb{D}^{1,2}$ Junran Liu $\mathbb{D}^{1,2}$ Hengheng Xiao $\mathbb{D}^{1,},{ }^{1,2}$ Yi Zhang $\mathbb{D}^{3}$, Qingcheng $M o \mathbb{D}^{1,2}$ \\ Jiyang Shen (iD, ${ }^{1,2}$ and Jun Shi $\left.{ }^{4}\right)^{4}$ \\ ${ }^{1}$ Key Lab of Structures Dynamic Behavior and Control of the Ministry of Education, Harbin Institute of Technology, \\ Harbin 150090, China \\ ${ }^{2}$ Key Lab of Smart Prevention and Mitigation of Civil Engineering Disasters of the \\ Ministry of Industry and Information Technology, Harbin Institute of Technology, Harbin 150090, China \\ ${ }^{3}$ Academy of Combat Support, Rocket Force University of Engineering, Xi'an 710025, China \\ ${ }^{4}$ School of Transportation Science and Engineering, Harbin Institute of Technology, Harbin 150090, China
}

Correspondence should be addressed to Hengheng Xiao; 18S033020@stu.hit.edu.cn and Yi Zhang; zhangyi_yantai@163.com

Received 11 September 2019; Accepted 18 January 2020; Published 18 February 2020

Academic Editor: Giovanni Minafò

Copyright (c) 2020 Yubin Tian et al. This is an open access article distributed under the Creative Commons Attribution License, which permits unrestricted use, distribution, and reproduction in any medium, provided the original work is properly cited.

This paper presents the results of an experimental research designed to investigate the combined effects of corrosion rate, concrete cover thickness, and stirrup spacing on the bond performance between reinforcement and concrete of reinforced concrete (RC) specimens. The RC specimens were immersed into sodium chloride solution to eliminate the passivation film on reinforcement. Then, an accelerated corrosion method was applied to corrode reinforcement embedded in concrete specimens. Pullout test was carried out to establish empirical formulas for ultimate slip and ultimate bond strength of RC specimens with three different corrosion rates, different concrete cover thicknesses, and different stirrup spacings. In addition, the bond-slip relation model was developed to predict and evaluate the bond performance of RC specimens. Finally, the ultrasonic technology was used to detect the damage of RC specimens, and the corresponding nonlinear coefficient $\beta$ was proposed to characterize the damage degree of RC specimens. The susceptibility of $\beta$ on the damage of specimens was compared with that of ultrasonic velocity, indicating $\beta$ was more appropriate to evaluate the damage of RC specimens.

\section{Introduction}

Reinforced concrete (RC) structures have become one of the most widely used structure forms due to their low cost and strong applicability. However, corrosion of reinforcement may appear extensively in RC structures after years of service, especially for those in environments with large amounts of corrosive media [1-3]. The corrosion products have characteristics of volumetric expansion and easy exfoliation, resulting in the damage of bonding interface and the cracking of cover concrete [4-7]. Accordingly, the corrosion of reinforcement is the main cause of the predominant deterioration for RC structures $[8,9]$. It is of great significance to clarify the effects of corrosion level on the bond performance between reinforcement and concrete.
In fact, massive money has been spent on preventing and repairing the damage to $\mathrm{RC}$ structures caused by corrosion. Moreover, the interaction between reinforcement and concrete is quite complicated, and numerous research studies have been carried out to investigate the influences of corrosion on the RC structures. For instance, Fang et al. designed a series of specimens with different corrosion rates and different types of steel bars, and the pullout test was conducted to evaluate the effects of corrosion on bond and bond-slip behavior of RC specimens. The results showed that the bonding strength of specimens with smooth bar increased with the rising corrosion level, up to a relatively high degree of corrosion [10]. Francois and Arliguie investigated the effect of both cracking and microcracking on the service life of loaded RC and found 
that it was the corrosion of reinforcement caused by chloride ions penetrating through the cracks that reduced the service life of the RC elements [11]. Torres-Acosta et al. conducted an experimental investigation on the flexure capacity loss of RC beams with corroded reinforcement. The research results indicated that the flexure load capacity decreased mainly due to the formation of pits on the reinforcement surface [12-17]. Lee et al. carried out the pullout test to analyze the effect of reinforcement corrosion on the bond properties between concrete and reinforcement and verified that the maximum bonding strength and the bond rigidity of specimens decreased in proportion to the increase in corrosion rate [18]. Davis et al. applied distributed fibre optic sensors to detect the impact of corrosion on the bond performance of RC specimens, which made the monitor of pitting corrosion possible and provided insights into the bond performance between concrete and reinforcement of corroded specimens [19]. Tondolo conducted the pullout test to investigate the bond behavior of RC specimens with different corrosion levels and stirrup spacings, and the results showed that the corrosion rate and stirrup played a significant role in affecting the ultimate bonding strength of RC specimens [20]. Bhargava et al. proposed analytical and empirical models for the bonding strength of corroded reinforcement, and the predicted results by the models were in reasonably good agreement with the experimental values [21]. Auyeung et al. conducted an experiment to investigate the effect of corrosion on the loss of bond strength between the steel bar and concrete. Also, the results indicated that the bond strength and bond stiffness were improved with a small amount of corrosion, while decreasing considerably when the mass loss of steel bar exceeded 2\% [22]. In addition, in order to evaluate the effects of corrosion on the performance of corroded RC structures, many research studies on their damage detection also have been conducted based on experiment and numerical simulation. Yeih and Huang applied the amplitude attenuation method in ultrasonic testing to evaluate the corrosion damage of RC members and verified that the detection method had good performance in revealing the damage of $\mathrm{RC}$ members [23]. Liang and Su used the impact-echo method to detect the corrosion of reinforcement in the concrete blocks. The displacement spectrum obtained from the impact-echo method should be transferred as the acceleration spectrum to predict the corrosion damage of RC specimens [24]. Watanabe et al. applied ultrasonic testing to detect the damage of concrete and cracking under an electrolytic corrosion test. The results indicated that ultrasonic evaluation could detect the corrosion and corrosion-induced cracking inside concrete at the dormant and the initiation stage prior to the acceleration stage [25]. Capozucca conducted the static and dynamic analysis to detect the damage because of corrosion in prestressed RC beams. The result showed that a decrease in stiffness and an increase in curvature are caused by the corrosion of reinforcement [26]. All these research achievements have greatly promoted the evaluation of bond performance and damage detection of corroded RC structures. Nevertheless, there are still some problems puzzling the researcher and need to be resolved, as summarized below:

(1) The bond performance between reinforcement and concrete is affected by many factors, leading to a complicated interaction between these two materials. The parameter study on the bond-slip behavior of corroded RC specimens is insufficient, which limits the revealing of the actual mechanism of the bond performance.

(2) The ultrasonic testing is widely applied in the damage detection of corroded RC structures. But, it is inaccurate only through the attenuation of the ultrasonic velocity to evaluate the damage degree of $\mathrm{RC}$ specimens. A new parameter is expected to describe the damage of RC specimens and further evaluate the change of bond performance between reinforcement and concrete.

In view of these two problems, the authors designed 27 $\mathrm{RC}$ specimens with different parameters, including concrete cover thickness, corrosion rate, and stirrup spacing. Through the pullout tests of RC specimens, the bonding strength and slip between reinforcement and concrete were tested. The empirical equations of bonding strength and slip about respective parameters were fitted, and the bond-slip relation models were established to describe the whole damaged process. Then, the ultrasonic testing was applied to detect the damage of corroded RC specimens, and the nonlinear coefficient was proposed to evaluate the RC specimens' damage degree, which was more appropriate than using the ultrasonic velocity.

\section{Experimental Procedure}

2.1. Design and Fabrication of Specimens. As shown in Figure 1(a), the size of the specimen was designed as a prism of $160 \mathrm{~mm} \times 160 \mathrm{~mm} \times 250 \mathrm{~mm}$, and deformed longitudinal reinforcement of $20 \mathrm{~mm}$ diameter was buried in the corresponding positions of the specimens with the anchorage length of $200 \mathrm{~mm}$, so as to ensure enough anchorage length. Meanwhile, smooth stirrup of $10 \mathrm{~mm}$ in diameter and $80 \mathrm{~mm} \times 90 \mathrm{~mm}$ in side length was connected to the longitudinal reinforcement, with the spacing of $100 \mathrm{~mm}$, $150 \mathrm{~mm}$ (a single stirrup could be seen as a spacing of $0 \mathrm{~mm}$ ), as shown in Figure 1(b). The yield strength of deformed longitudinal reinforcement and smooth stirrup is $400 \mathrm{MPa}$, and the elastic modulus is $210 \mathrm{GPa}$. The designed strength of the Portland cement used in the specimen is $42.5 \mathrm{MPa}$. The water-cement ratio is 0.45 . The ratio of the coarse aggregate to the fine aggregate is 1.78 by weight. The concrete cover thickness was designed as $35 \mathrm{~mm}, 45 \mathrm{~mm}$, and $55 \mathrm{~mm}$, respectively. A rigid PVC casing pipe with a length of $50 \mathrm{~mm}$ was arranged at the loaded end, eliminating the local squeezing effect of the pressure-bearing steel plate on the end of the specimen. Table 1 lists the group number, size, stirrup spacing, corrosion rate, and concrete cover thickness. A specimen is named according to the corrosion rate, concrete cover thickness, and stirrup spacing. For example, " $w$," " $c$," and " $s$ " in " $C w-c-s$ " denote the corrosion rate, 


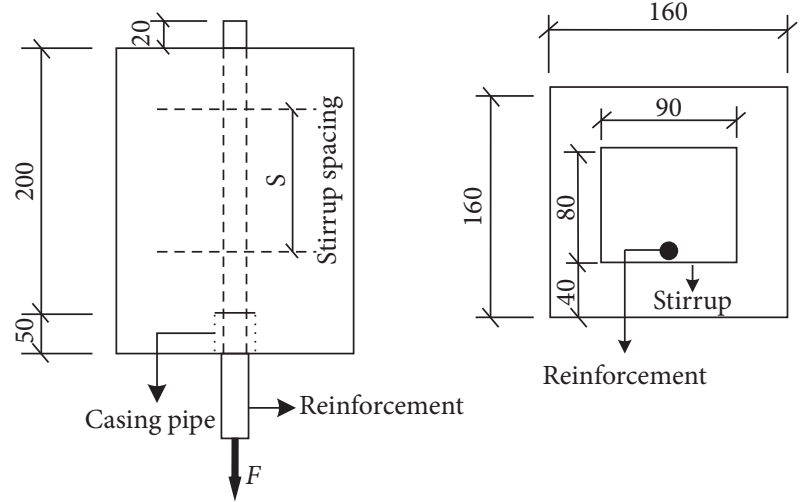

Figure 1: Geometric configuration of the specimen (units: mm).

TABle 1: Parameters and dimensions of specimens (units: $\mathrm{mm}$ ).

\begin{tabular}{lccc}
\hline $\begin{array}{l}\text { Specimen } \\
\text { number }\end{array}$ & $\begin{array}{c}\text { Stirrup } \\
\text { spacing }\end{array}$ & $\begin{array}{c}\text { Corrosion } \\
\text { rate }(\%)\end{array}$ & $\begin{array}{c}\text { Cover } \\
\text { thickness }\end{array}$ \\
\hline C0-35-0 & 0 & 0 & 35 \\
C7-35-0 & 0 & 7 & 35 \\
C15-35-0 & 0 & 15 & 35 \\
C0-35-100 & 100 & 0 & 35 \\
C7-35-100 & 100 & 7 & 35 \\
C15-35-100 & 100 & 15 & 35 \\
C0-35-150 & 150 & 0 & 35 \\
C7-35-150 & 150 & 7 & 35 \\
C15-35-150 & 150 & 15 & 35 \\
C0-45-0 & 0 & 0 & 45 \\
C7-45-0 & 0 & 7 & 45 \\
C15-45-0 & 0 & 15 & 45 \\
C0-45-100 & 100 & 0 & 45 \\
C7-45-100 & 100 & 7 & 45 \\
C15-45-100 & 100 & 15 & 45 \\
C0-45-150 & 150 & 0 & 45 \\
C7-45-150 & 150 & 7 & 45 \\
C15-45-150 & 150 & 15 & 45 \\
C0-55-0 & 0 & 0 & 55 \\
C7-55-0 & 0 & 7 & 55 \\
C15-55-0 & 0 & 15 & 55 \\
C0-55-100 & 100 & 0 & 55 \\
C7-55-100 & 100 & 7 & 55 \\
C15-55-100 & 100 & 15 & 55 \\
C0-55-150 & 150 & 0 & 55 \\
C7-55-150 & 150 & 7 & 55 \\
C15-55-150 & 150 & 15 & \\
\hline & & & 55 \\
\hline
\end{tabular}

concrete cover thickness, and stirrup spacing, respectively, as shown in Table 1.

2.2. Corrosion Scheme for Longitudinal Reinforcement. The corrosion of reinforcement in RC structures could be generally divided into two types: electrochemical corrosion and stray current corrosion. The latter case does not occur frequently because it is necessary to satisfy certain conditions to induce reinforcement corrosion. In contrast, electrochemical corrosion of reinforcement is ubiquitous in nature and becomes the main cause of reinforcement corrosion, as shown in Figure 2. The procedure of electrochemical corrosion was generally divided into three stages as follows.

The oxidation reaction in the anode region:

$$
\mathrm{Fe}-2 \mathrm{e} \longrightarrow \mathrm{Fe}^{2+}
$$

The reduction reaction in the cathode region:

$$
\mathrm{O}_{2}+2 \mathrm{H}_{2} \mathrm{O}+4 \mathrm{e} \longrightarrow 4 \mathrm{OH}^{-}
$$

The formation of corrosion production:

Electrons released by oxidation in the anode region transfer along reinforcement to the cathode region, and the $\mathrm{Fe}^{2+}$ produced by the chemical reaction expands to the ambient solution simultaneously. The $\mathrm{OH}^{-}$in the cathode region gradually diffuses to the anode region through the pore of the specimen and combines with the $\mathrm{Fe}^{2+}$ in the anode region, generating insoluble $\mathrm{Fe}(\mathrm{OH})_{2}$. When oxygen is sufficient, $\mathrm{Fe}(\mathrm{OH})_{2}$ is further oxidized to $\mathrm{Fe}(\mathrm{OH})_{3}$ through the following chemical reaction:

$$
4 \mathrm{Fe}(\mathrm{OH})_{2}+\mathrm{O}_{2}+2 \mathrm{H}_{2} \mathrm{O} \longrightarrow \mathrm{Fe}(\mathrm{OH})_{3}
$$

The corrosion product $\left(\mathrm{Fe}_{2} \mathrm{O}_{3} \cdot \mathrm{H}_{2} \mathrm{O}\right)$ with a loose and porous structure is engendered as a result of the dehydration of $\mathrm{Fe}(\mathrm{OH})_{3}$ :

Under the progressive hypoxic conditions, black $\mathrm{Fe}_{3} \mathrm{O}_{4}$ is produced due to the incomplete oxidation of $\mathrm{Fe}(\mathrm{OH})_{3}$ :

$$
6 \mathrm{Fe}(\mathrm{OH})_{2}+\mathrm{O}_{2} \longrightarrow 2 \mathrm{Fe}_{3} \mathrm{O}_{4}+6 \mathrm{H}_{2} \mathrm{O}
$$

The volume of the corrosion product is almost several times than that of the original, exerting tension on the concrete around the reinforcement. As the corrosion turns worse, corrosive cracks in protective layer concrete begin to emerge when the corrosion-induced expansive force is beyond the ultimate tensile strength of concrete, which would further accelerate the corrosion of reinforcement.

Although the reinforcement corrosion of the RC structure is a long process in engineering, the corrosion rate obtained in the laboratory is much stronger than that observed in a real structure, which could save considerable time and effort [27]. Therefore, the accelerated corrosion method is widely used in the laboratory to investigate the mechanical properties of corroded RC specimens. Here, authors carried out the corrosion test of reinforcement through the constant current acceleration method. The specific test process could be divided into two stages.

2.2.1. The Calculation of Conduction Time. Based on Faraday's law of electrolysis, the magnitude of current and conduction time can be determined by the following equation:

$$
\Delta m=M \times \frac{I t}{n F},
$$

where $\Delta m$ is the weight of reinforcement involved in chemical reaction of corrosion; $M$ represents the molar mass of material; $I$ is the magnitude of current; $t$ expresses the conduction time; $n$ is the number of electrons in the electrode reaction measurement equation; and $F$ is Faraday's 


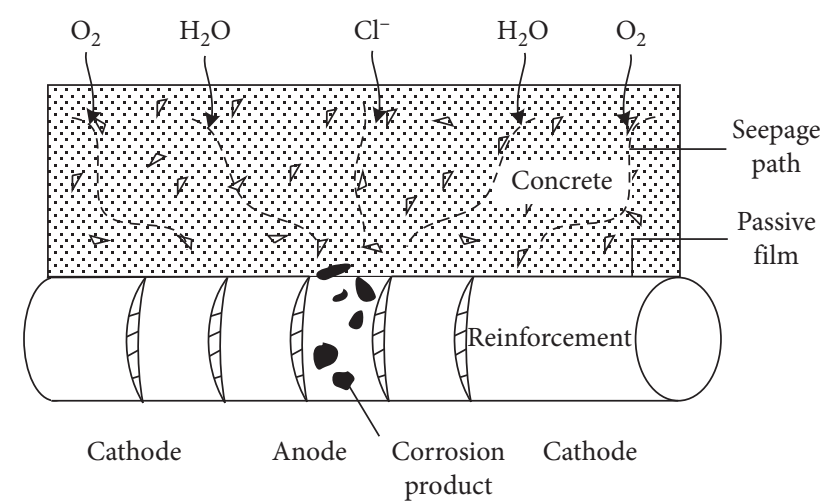

FIgURE 2: The schematic diagram of the electrochemical principle.

constant of $96500 \mathrm{C} \cdot \mathrm{mol}^{-1}$. The diameter of longitudinal reinforcement is $20 \mathrm{~mm}$, and the length of the corroded section is $270 \mathrm{~mm}$. Then, the weight of longitudinal reinforcement in the corroded section can be calculated through the following equation:

$$
\Delta m=3.14 \times 1 \mathrm{~cm} \times 1 \mathrm{~cm} \times 27 \mathrm{~cm} \times 7.85 \mathrm{~g} / \mathrm{cm}^{3}=665.52 \mathrm{~g} .
$$

For reinforcement with the corrosion rate of $7 \%, \Delta m$ is $46.59 \mathrm{~g}$. For reinforcement with the corrosion rate of $15 \%$, $\Delta m$ is $99.83 \mathrm{~g}$. The molar mass and electrons of $\mathrm{Fe}$ is $56 \mathrm{~kg} \cdot \mathrm{mol}^{-1}$ and 2, respectively. Taking the reinforcement with the corrosion rate of $7 \%$ as an example, the relation of the magnitude of current and conduction time can be obtained through substituting the abovementioned parameters into the following equation:

$$
I t=160.56 \mathrm{~A} \cdot \mathrm{h} .
$$

When the magnitude of current is $1 \mathrm{~A}, 160$ hours is needed to corrode the reinforcement. Considering the instability of current, the actual conduction time is 30\% more than the theoretical time to achieve the designed corrosion rate, so the actual corrosion time is 208 hours. Also, the corrosion time of specimens with a corrosion rate of $15 \%$ is 445 hours.

2.2.2. The Procedure of Corrosion Experiment. As shown in Figure 3, in order to provide an environment for chemical reaction, $\mathrm{NaCl}$ solution with a mass concentration of $5 \%$ was injected into the plastic vessel. The specimens were immersed in the solution for 48 hours to ensure the sufficient contact of solution and specimens and remove the passive film on the reinforcement. The length of the corrosion section was $200 \mathrm{~mm}$, and the original weight was $455 \mathrm{~g}$ before corrosion. The reinforcement was connected in series to the positive pole of the direct current (DC) power supply, and the copper strip was connected to the negative pole. After adjusting the magnitude of current to the default value, the reinforcement was continued to be corroded until achieving the calculated corrosion time. Table 2 lists the measured corrosion rates of reinforcement in specimens.

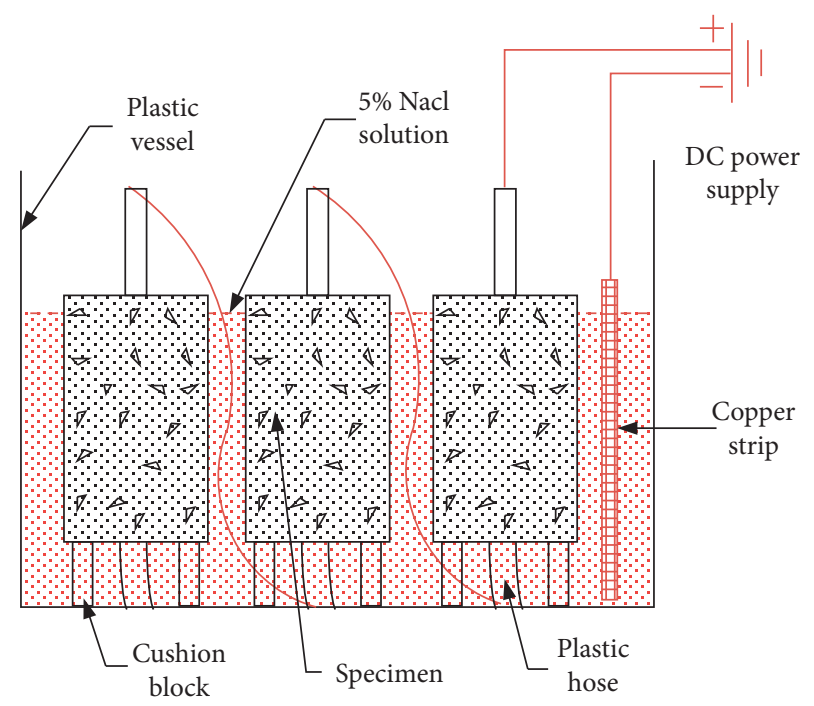

FIgURE 3: The schematic diagram of the electrochemical principle.

TABLE 2: The measuring corrosion rate of reinforcement.

\begin{tabular}{lcc}
\hline $\begin{array}{l}\text { Specimen } \\
\text { number }\end{array}$ & $\begin{array}{c}\text { Corroded weight } \\
(\mathrm{g})\end{array}$ & $\begin{array}{c}\text { Measuring corrosion rate } \\
(\%)\end{array}$ \\
\hline C7-35-0 & 413 & 7.1 \\
C7-35-150 & 415 & 6.8 \\
C7-35-100 & 416 & 6.5 \\
C7-45-0 & 414 & 6.9 \\
C7-45-150 & 412 & 7.5 \\
C7-45-100 & 412 & 7.4 \\
C7-55-0 & 411 & 7.7 \\
C7-55-150 & 416 & 6.6 \\
C7-55-100 & 414 & 7.0 \\
C15-35-0 & 378 & 15.2 \\
C15-35-150 & 378 & 15.0 \\
C15-35-100 & 376 & 15.6 \\
C15-45-0 & 380 & 14.6 \\
C15-45-150 & 379 & 14.9 \\
C15-45-100 & 377 & 15.3 \\
C15-55-0 & 381 & 14.4 \\
C15-55-150 & 374 & 15.9 \\
C15-55-100 & 383 & 14.0 \\
\hline
\end{tabular}

Also, the average corrosion rates of specimens are $7 \%$ and $15 \%$, respectively.

2.3. Experimental Apparatus and Measuring Scheme. As shown in Figures 4(a) and 4(b), a small groove was cut in the reinforcement to install the strain gauges. Figures $4(\mathrm{c})$ and 4(d) show the pullout test apparatus and the layout of the force sensor. Two high-precision LVDT displacement meters were equipped to measure the vertical deflections of the specimen. The slip between reinforcement and concrete could be calculated through applying the total displacement to subtract the elongation of reinforcement. Monotonically increasing loads were adopted in the tests until the free end slip of reinforcement reached $20 \mathrm{~mm}$. The load speeding was $60 \mathrm{~N} / \mathrm{s}$ in the initial stage and changed to 


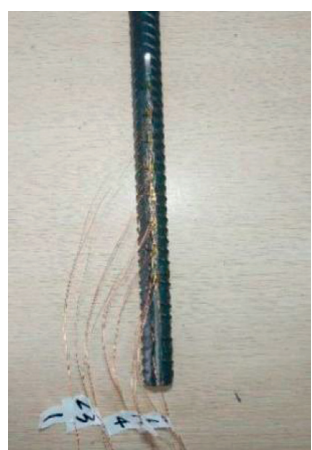

(a)

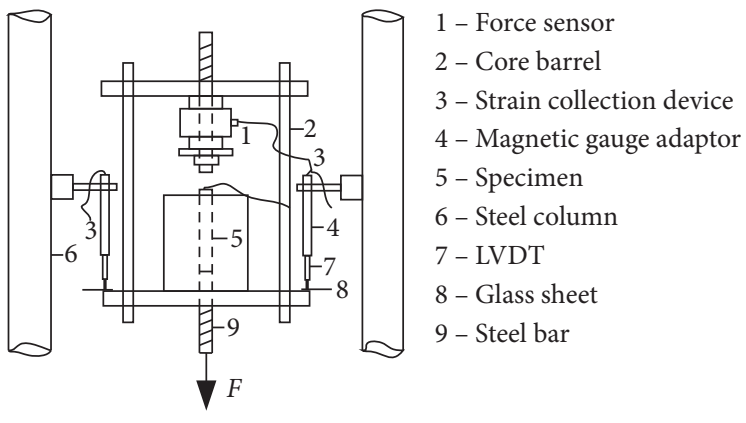

(c)

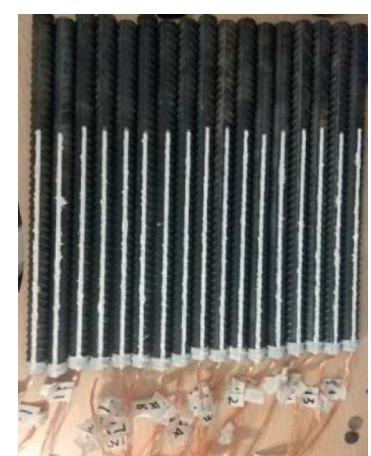

(b)

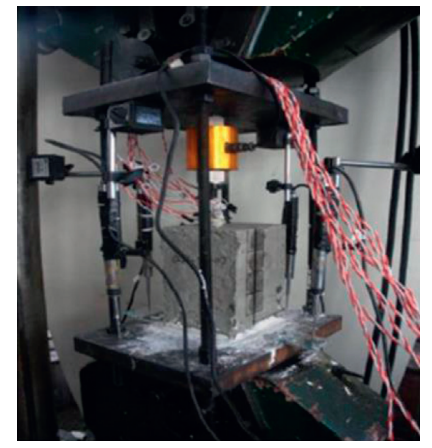

(d)

FIGURE 4: Loading apparatus and the layout of the measuring instrument: (a) the layout of the strain gauge; (b) waterproofing treatment of reinforcement; (c) the schematic view of the loading apparatus; and (d) the loading test in site.

$0.1 \mathrm{~mm} / \mathrm{min}$ until achieving the ultimate bonding strength. It should be highlighted that preloading was performed to ensure the contact between the steel plate and the specimen, and the preload was generally $20 \mathrm{kN}$.

\section{Investigation of the Experimental Data}

3.1. The Ultimate Slip $S_{u}$ and the Ultimate Bonding Strength $\tau_{u}$ of Specimens. The calculation method of ultimate slip $S_{u}$ has been described in Section 2.3. The ultimate bonding strength between reinforcement and concrete can be obtained from the following equation:

$$
\tau_{u}=\frac{P_{u}}{\pi d l}
$$

where $P_{u}$ is the ultimate pullout resistance of the specimen; $d$ is the diameter of longitudinal reinforcement, and $l$ is the anchorage length of reinforcement, which is $200 \mathrm{~mm}$.

Table 3 lists the ultimate slip, pullout resistance, and bonding strength of each specimen. Based on the data in Table 3, the effects of parameters (corrosion rate, concrete cover thickness, and stirrup spacing) on the pullout behavior of reinforcement can be revealed. The concrete cover thickness is positively correlated with ultimate slip and bonding strength. In addition, reducing the stirrup spacing is also conducive to enhance the ultimate slip and bonding strength between reinforcement and concrete. When the
TABle 3: The measuring results of experimental specimens.

\begin{tabular}{lccc}
\hline Specimen & $P_{u}(\mathrm{kN})$ & $\tau_{u}(\mathrm{MPa})$ & Slip \\
\hline C0-35-0 & 116 & 9.31 & 9.17 \\
C0-35-150 & 123 & 9.79 & 9.61 \\
C0-35-100 & 126 & 10.03 & 11.58 \\
C0-45-0 & 124 & 9.87 & 9.65 \\
C0-45-150 & 126 & 10.03 & 11.29 \\
C0-45-100 & 135 & 10.75 & 12.37 \\
C0-55-0 & 152 & 12.10 & 13.65 \\
C0-55-150 & 155 & 12.34 & 14.05 \\
C0-55-100 & 160 & 12.74 & 18.19 \\
C7-35-0 & 107 & 8.52 & 6.79 \\
C7-35-150 & 109 & 8.68 & 8.21 \\
C7-35-100 & 115 & 9.16 & 8.93 \\
C7-45-0 & 121 & 9.63 & 7.62 \\
C7-45-150 & 124 & 9.87 & 9.00 \\
C7-45-100 & 127 & 10.11 & 10.21 \\
C7-55-0 & 127 & 10.11 & 9.37 \\
C7-55-150 & 138 & 10.99 & 11.08 \\
C7-55-100 & 148 & 11.78 & 14.82 \\
C15-35-0 & 95 & 7.56 & 6.44 \\
C15-35-150 & 99 & 7.88 & 7.07 \\
C15-35-100 & 100 & 7.96 & 8.28 \\
C15-45-0 & 100 & 7.96 & 7.27 \\
C15-45-150 & 107 & 8.52 & 7.96 \\
C15-45-100 & 114 & 9.08 & 9.86 \\
C15-55-0 & 124 & 9.87 & 8.17 \\
C15-55-150 & 128 & 10.19 & 10.45 \\
C15-55-100 & 141 & 11.23 & 13.80 \\
\hline & & &
\end{tabular}


corrosion rate of reinforcement rises, the poor cohesiveness between corrosion product and concrete leads to the decline of ultimate slip and bonding strength.

3.2. The Parametric Analysis of Bond Behavior of $R C$ Specimens. In order to investigate the effect of test parameters on the ultimate slip and bonding strength of specimens, the experimental results of specimens with only one inconsistent parametric are used to make linear fitting. The relationship between ultimate bond performance and three parameters, including the corrosion rate $w$, the ratio of concrete cover thickness to the diameter of longitudinal reinforcement $c / d$, and the stirrup ratio $\rho_{\mathrm{sv}}$, is analyzed. The $\rho_{\text {sv }}$ of the specimen can be calculated through the following equation:

$$
\rho_{\mathrm{sv}}=\frac{n A_{\mathrm{sv}}}{b s}
$$

where $A_{\mathrm{sv}}$ is the area of stirrup; $n$ is the limb number of stirrup, and its value is $2 ; b$ is the width of specimen, and $s$ is stirrup spacing. The fitting formulas of ultimate slip and bonding strength are shown in Tables 4 and 5, respectively.

According to these two tables, the effects of three parameters on the bond performance of $\mathrm{RC}$ specimens could be revealed through investigating the change of coefficients in formulas in Tables 4 and 5, given as follows.

The corrosion of reinforcement in specimens leads to a reduction of the cross section of the reinforcement, and an appearance of the cracks because of the corroded expansion force produced by the corrosion products. In addition, the corrosion products with a loose and porous structure have definite water-adsorption ability, which largely destroys the bond performance between reinforcement and concrete. From equations about the corrosion rate, the coefficients of linear are negative, indicating a reduction in bonding strength with the increase in corrosion rate [28]. The interception of equations represents the original bonding strength and ultimate slip when the reinforcement is not corroded. In addition, adding the concrete cover thickness and reducing the stirrup spacing can enhance the bonding strength and ultimate slip through comparing the value of interception of specimens with different concrete cover thicknesses and stirrup spacings.

The concrete cover thickness also plays a significant role in restraining the longitudinal reinforcement and affecting the bond performance of specimens. For equations with $c / d$ as an independent variable, the coefficients of linear are positive, indicating an outstanding performance of specimens with the increase in concrete cover thickness. Moreover, when the corrosion rate of specimens remains unchanged, the increase in the bonding strength and slip becomes faster with the reduction of stirrup spacing. For the specimen with the same stirrup spacing, the bonding strength and slip of specimens with high corrosion rate increases faster than those of specimens with low corrosion rate.
The stirrup has a restraining effect on the transverse deformation of concrete near the longitudinal reinforcement, which could delay the development of vertical cracks to the surface of the specimen. For equations with stirrup ratio as an independent variable, the coefficients of linear are the largest among these three parameters, showing that the influences of stirrup ratio on the bond performance of specimens are more sensitive. Also, the stirrup ratio is positively correlated with the bond performance between reinforcement and concrete [29]. For the specimens with the same corrosion rate, the growth rate of bond performance is improved with the increase in concrete cover thickness.

Finally, the range of the coefficients in these formulas with the different corrosion rates, concrete cover thicknesses, and stirrup spacings is listed in Table 6 to sum up the variation of the coefficients and to give a more simplified formula. The $X$ in equations represents $w, c / d$, and $\rho_{\mathrm{sv}}$, respectively. The equations fitted by the actual tested data of specimens could contribute to improve the bond performance between concrete and reinforcement.

3.3. The Analysis of the Bond-Slip Relation Model. Recently, the bond-slip relation model of noncorroded RC is mainly used in the finite element (FE) simulation of corroded RC structures/members, resulting in unsatisfactory results. Therefore, the establishment of bond-slip relation considering different corrosion rates and multifactor coupling is of great significance for both FE simulation and safety evaluation of corroded RC structures/members. After calculating the average bond stress, the curves of average bond stress with slip are plotted. Also, the bond-slip curves of measured specimens with different stirrup spacings are plotted in the same figure for comparing. As shown in Figure 5, the group of C0-55-s is taken as an example, and the bond-slip curve could be divided into five stages during the pullout process, given as follows:

(1) Initial Slip Stage. In the initial stage of loading, the slip of longitudinal reinforcement at loading end is slight. Also, there is no slip at the free end. The average bond strength increases slowly with the slip at this stage.

(2) Accelerated Slip Stage. The relative slip between longitudinal reinforcement and concrete begins to emerge at the free end with increasing load. The chemical adhesive force of the bonding interface is destroyed, accelerating the slip between longitudinal reinforcement and concrete in the anchorage section. In addition, the slip also results the formation of tension cracks at the loading end.

(3) Splitting Stage. The average bonding strength further increases with the rising of load, and the tension cracks develop rapidly from the loading end to the free end. The bonding strength achieves its maximum value. It should be highlighted that the duration of this stage is short, so it is difficult to observe the corresponding phenomena. 
TABLE 4: The expression of the ultimate bonding strength and corresponding parameter.

\begin{tabular}{|c|c|c|c|c|c|c|c|c|}
\hline \multirow[t]{2}{*}{ Equation corrosion rate } & \multicolumn{2}{|c|}{$\tau_{u}=a_{\tau} \cdot \omega+b_{\tau}$} & \multirow[t]{2}{*}{ Equation cover thickness } & \multicolumn{2}{|c|}{$\begin{array}{c}\tau_{u}= \\
a_{\tau} \cdot c / d+b_{\tau}\end{array}$} & \multirow[t]{2}{*}{ Equation stirrup ratio } & \multicolumn{2}{|c|}{$\begin{array}{c}\tau_{u}= \\
a_{\tau} \cdot \rho_{\mathrm{sv}}+b_{\tau}\end{array}$} \\
\hline & $a_{\tau}$ & $b_{\tau}$ & & $a_{\tau}$ & $b_{\tau}$ & & $a_{\tau}$ & $b_{\tau}$ \\
\hline $\mathrm{C} w-35-0$ & -11.68 & 9.32 & $\mathrm{C} 0-c / d-0$ & 2.79 & 4.15 & $\mathrm{C} 0-35-\rho_{\mathrm{sv}}$ & 33.98 & 8.75 \\
\hline$C w-35-150$ & -12.67 & 9.71 & $\mathrm{C} 0-c / d-150$ & 2.55 & 4.98 & $\mathrm{C} 0-45-\rho_{\mathrm{sv}}$ & 46.12 & 8.91 \\
\hline $\mathrm{C} w-35-100$ & -13.83 & 10.06 & $\mathrm{C} 0-c / d-100$ & 2.71 & 5.08 & $\mathrm{C} 0-55-\rho_{\mathrm{sv}}$ & 32.21 & 11.48 \\
\hline $\mathrm{C} w-45-0$ & -12.93 & 10.1 & $\mathrm{C} 7-c / d-0$ & 1.59 & 5.84 & $\mathrm{C} 7-35-\rho_{\mathrm{sv}}$ & 33.07 & 7.85 \\
\hline $\mathrm{C} w-45-150$ & -10.23 & 10.8 & $\mathrm{C} 7-c / d-150$ & 2.31 & 4.65 & $\mathrm{C} 7-45-\rho_{\mathrm{sv}}$ & 23.51 & 9.2 \\
\hline $\mathrm{C} w-45-100$ & -11.18 & 10.8 & $C 7-c / d-100$ & 2.62 & 4.46 & $\mathrm{C} 7-55-\rho_{\mathrm{sv}}$ & 81.32 & 8.65 \\
\hline $\mathrm{C} w-55-0$ & -14.59 & 11.76 & $\mathrm{C} 15-c / d-0$ & 2.31 & 3.27 & C15-35- $\rho_{\mathrm{sv}}$ & 18.3 & 7.28 \\
\hline $\mathrm{C} w-55-150$ & -14.23 & 12.22 & $\mathrm{C} 15-c / d-150$ & 2.31 & 3.67 & C15-45- $\rho_{\mathrm{sv}}$ & 54.86 & 6.96 \\
\hline $\mathrm{C} w-55-100$ & -9.99 & 12.65 & $\mathrm{C} 15-c / d-100$ & 3.27 & 2.07 & C15-55- $\rho_{\mathrm{sv}}$ & 70.5 & 8.43 \\
\hline
\end{tabular}

TABLE 5: The expression of the ultimate slip and the corresponding parameter.

\begin{tabular}{lcccccr}
\hline & \multicolumn{2}{c}{$S_{u}=a_{s} \cdot \omega+b_{s}$} & Equation & \multicolumn{2}{c}{$\begin{array}{c}S_{u}= \\
a_{s} \cdot c / d+b_{s}\end{array}$} & \multicolumn{2}{c}{$\begin{array}{c}S_{u}= \\
\text { Equation stirrup ratio }\end{array}$} \\
& $a_{s}$ & $b_{s}$ & Cover thickness & $a_{s}$ & $b_{s}$ & $\rho_{\text {sv }}+b_{s}$ \\
$b_{s}$
\end{tabular}

TABLE 6: The unified empirical formula.

\begin{tabular}{lcccc}
\hline & \multicolumn{2}{c}{$\tau_{u}=a_{\tau} \cdot X+b_{\tau}$} & $S_{u}=a_{s} \cdot X+b_{s}$ & $b_{s}$ \\
\hline Corrosion rate $(w)$ & $a_{\tau}$ & $b_{\tau}$ & $-23 \leq a_{s} \leq-16$ & $8.8 \leq b_{s} \leq 13.59$ \\
Cover thickness $(c / d)$ & $-14.59 \leq a_{\tau} \leq-10$ & $9.32 \leq b_{\tau} \leq 12.65$ & $1.73 \leq a_{s} \leq 4.44$ & $1.66 \leq b_{s} \leq 3.4$ \\
Stirrup ratio $\left(\rho_{\mathrm{sv}}\right)$ & $2.31 \leq a_{\tau} \leq 3.27$ & $3.27 \leq b_{\tau} \leq 5.84$ & $93.25 \leq a_{s} \leq 281.5$ & $2.82 \leq b_{s} \leq 8.42$ \\
\hline
\end{tabular}

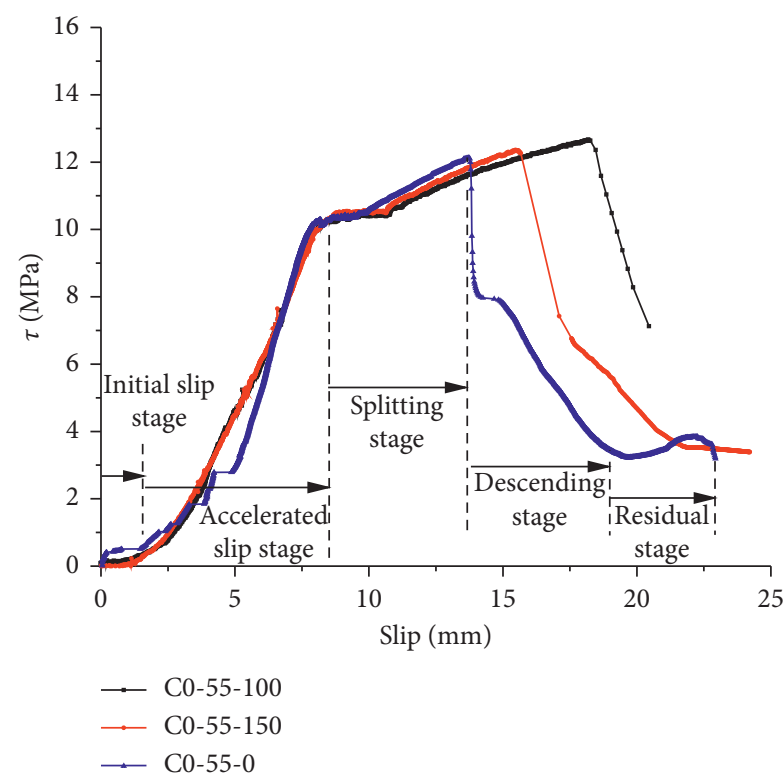

Figure 5: The bond-slip curves of C0-55-s.
(4) Descending Stage. After reaching the ultimate bond strength of the specimen, the rapid development of cracks leads to the serious damage of the bonding surface. Therefore, the average bonding strength decreases dramatically, and the slip between longitudinal reinforcement and concrete increases rapidly at this stage.

(5) Residual Stage. When the slip of longitudinal reinforcement exceeds a certain value, the average bonding strength remains almost unchanged instead of continuing to decline. After a period of stable platform, the slip increases continuously until the specimen is destroyed.

Based on the analysis of the measured bond-slip curves, an updated bond-slip relation model for corroded RC is proposed through introducing three variables: concrete cover thickness, corrosion rate, and stirrup ratio. The bondslip relation model consists of four stages, including the slip stage, splitting stage, descending stage, and residual stage. The formulas are as follows: 


$$
\tau= \begin{cases}k_{1} S, & 0 \leq S \leq S_{\mathrm{cr}}, \\ \tau_{\mathrm{cr}}+k_{2}\left(S-S_{\mathrm{cr}}\right), & S_{\mathrm{cr}}<S \leq S_{u}, \\ \tau_{u}+k_{3}\left(S-S_{u}\right), & S_{u}<S \leq S_{r}, \\ \tau_{r}, & S_{r} \leq S,\end{cases}
$$

where $\tau$ is the average bonding strength; $S$ is the slip between longitudinal reinforcement and concrete; $\tau_{u}$ and $S_{u}$ are the ultimate bonding strength and slip, respectively; $\tau_{\mathrm{cr}}$ is the cracking bonding strength, taking the value of $0.9 \tau_{u} ; S_{\mathrm{cr}}$ is the cracking slip, taking the value of $0.9 S_{u} ; \tau_{r}$ and $S_{r}$ are the residual bonding strength and the residual slip, respectively; $k_{1}, k_{2}$, and $k_{3}$ are the slope of the first three stages and could be calculated by the following equations:

$$
\begin{aligned}
& k_{1}=\frac{\tau_{\mathrm{cr}}}{S_{\mathrm{cr}}}, \\
& k_{2}=\frac{\left(\tau_{u}-\tau_{\mathrm{cr}}\right)}{\left(S_{u}-S_{\mathrm{cr}}\right)}, \\
& k_{3}=\frac{\left(\tau_{r}-\tau_{u}\right)}{\left(S_{r}-S_{u}\right) .}
\end{aligned}
$$

According to the measured experimental data, the $\tau_{u}, S_{u}$, $\tau_{r}$, and $S_{r}$ are fitted as follows:

$$
\begin{aligned}
& \tau_{u}=\tau_{\text {con }}+\tau_{\text {st }}=\left(k_{\text {con }} \cdot \frac{c}{d}+\tau_{0}\right)+\left(k_{\text {st }} \rho_{\text {sv }}\right), \\
& =\left(k_{\mathrm{con}} \cdot \frac{c}{d}+\tau_{0}\right)+\left(A \cdot \frac{c}{d}+k_{0}\right) \rho_{\mathrm{sv}}, \\
& \left\{\begin{array}{l}
k_{\text {con }}=-10.18 \omega+2.31, \\
\tau_{0}=8.58 \omega+4.47, \\
A=211.27 \omega+24.63, \\
k_{0}=-399.43 \omega-17.59,
\end{array}\right. \\
& S_{u}=S_{\mathrm{st}}+S_{0}=k_{u} \cdot \rho_{\mathrm{sv}}+S_{0}, \\
& =\left(k_{\omega} \cdot \frac{c}{d}+k_{0}\right) \rho_{\mathrm{sv}}+k_{s} \cdot \frac{c}{d}+k_{s 0}, \\
& \left\{\begin{array}{l}
k_{\omega}=472.28 \omega-125.83 \\
k_{0}=-1024 \omega-116.58 \\
k_{s}=-24.68 \omega+2.05 \\
k_{s 0}=32.58 \omega+2.69
\end{array}\right. \\
& \frac{\tau_{r}}{\tau_{u}}=(-9.8 \omega+3.09) \rho_{\mathrm{sv}}+0.19, \\
& \frac{S_{r}}{S_{u}}=(-86.87 \omega-8.31) \rho_{\mathrm{sv}}+3.94 \omega+1.85 .
\end{aligned}
$$

After obtaining the bond-slip relation model, the predicted bond-slip curves of specimens are plotted to compare with measured bond-slip curves, as shown in Figure 6. The predicted results are basically consistent with the experimental results, verifying the accuracy of the bond-slip relation model proposed above.

\section{Damage Testing of the Corroded RC by Ultrasonic Technology}

4.1. Relationship between Corrosion Rate and Nonlinear Coefficient. Ultrasonic testing was carried out on the specimens before and after corrosion to obtain the amplitude of ultrasonic time-domain maps in the two stages of corrosion. The power spectrum amplitude maps can be obtained through the method of fast Fourier transform, from which the fundamental amplitude and the second harmonic can be extracted. Table 7 lists the measured average values of the points on each specimen, and the nonlinear coefficient $\beta$ is calculated by the following equation:

$$
\beta=\left(\frac{A_{2}}{A_{1}}\right)^{2},
$$

where $A_{1}$ is average value of fundamental wave amplitude and $A_{2}$ is the amplitude of the second harmonic.

As shown in Figure 7, the second harmonic amplitude, $A_{2}$, increases with the increase in corrosion rate, $w$. When $w$ is 0,7 , and 15 , the corresponding average amplitude is 3.74 , 5.83, and 6.90, respectively. Therefore, the amplitude is nonlinearly increasing, because corrosion products cover on the surface of reinforcement after corrosion. With the accumulation of corrosion products, the volume is larger than the reduced volume of reinforcement corrosion, resulting in small cracks appearing in the bonding interface between reinforcement and concrete. As the development of corrosion, the cracks gradually extended toward the surface of the specimen until penetration. In this process, the damage of the specimen was intensified due to the development of cracks, and the nonlinear characteristics of ultrasonic became more and more obvious. When the cracks penetrated through and corrosion products fell out of the cracks, the crack width development of the specimen was relieved. Moreover, with the increase of the cracks, the damage of ultrasonic signal energy gradually increased, so the increasing speed of the second harmonic wave slowed down.

At the same time, as shown in Figure 8, the nonlinear coefficients under different corrosion rates are analyzed, which shows the similar law with Figure 7 . Therefore, the fundamental amplitude changes slightly with the increase in corrosion rate.

In combination with the experimental law, the nonlinear curve fitting is conducted to investigate the influence between different corrosion rates and nonlinear coefficients, as shown in Figure 8. The fitting formula can be established as follows:

$$
\beta=e^{-0.00243 w^{2}+0.0826 w-6.055},
$$

where $\beta$ is the nonlinear coefficient; $w$ is the corrosion rate $(0 \leq w \leq 15 \%)$. 


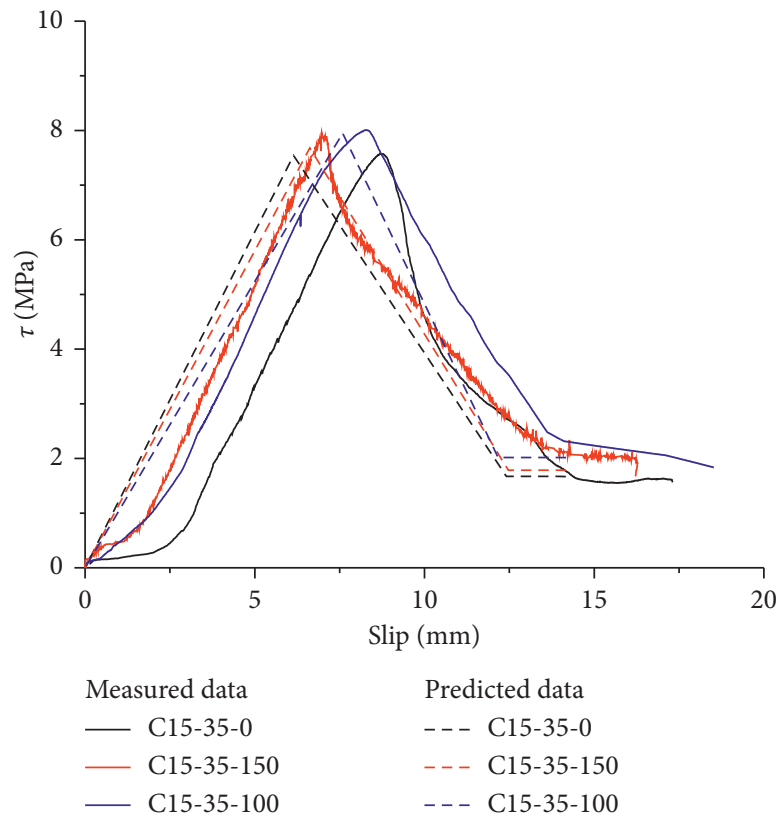

Figure 6: The comparison between predicted data and measured data.

TABLE 7: The measured experimental data and nonlinear coefficient.

\begin{tabular}{|c|c|c|c|c|c|c|c|c|c|}
\hline \multirow{2}{*}{ Corrosion rate specimen } & \multicolumn{3}{|c|}{$w=0 \%$} & \multicolumn{3}{|c|}{$w=7 \%$} & \multicolumn{3}{|c|}{$w=15 \%$} \\
\hline & $A_{1}$ & $A_{2}$ & $\beta$ & $A_{1}$ & $A_{2}$ & $\beta$ & $A_{1}$ & $A_{2}$ & $\beta$ \\
\hline $\mathrm{C} w-35-0$ & 37.19 & 4.10 & $2.96 E-03$ & 48.43 & 6.35 & $3.41 E-03$ & 36.73 & 7.00 & $5.19 E-03$ \\
\hline $\mathrm{C} w-35-150$ & 39.24 & 3.45 & $2.24 E-03$ & 36.71 & 5.59 & $4.15 E-03$ & 37.33 & 6.47 & $4.64 E-03$ \\
\hline $\mathrm{C} w-35-100$ & 37.77 & 3.85 & $2.70 E-03$ & 35.63 & 5.62 & $4.42 E-03$ & 42.59 & 7.75 & $4.27 E-03$ \\
\hline $\mathrm{C} w-45-0$ & 39.16 & 3.67 & $2.39 E-03$ & 43.91 & 5.49 & $2.85 E-03$ & 40.77 & 6.65 & $4.00 E-03$ \\
\hline $\mathrm{C} w-45-150$ & 44.47 & 3.66 & $1.85 E-03$ & 39.79 & 6.26 & $3.95 E-03$ & 35.95 & 7.21 & $5.58 E-03$ \\
\hline $\mathrm{C} w-45-100$ & 44.65 & 3.73 & $1.87 E-03$ & 36.52 & 5.56 & $4.17 E-03$ & 36.76 & 6.80 & $5.03 E-03$ \\
\hline $\mathrm{C} w-55-0$ & 39.87 & 4.19 & $2.64 E-03$ & 37.58 & 6.00 & $4.25 E-03$ & 38.18 & 7.27 & $4.85 E-03$ \\
\hline $\mathrm{C} w-55-150$ & 42.74 & 3.40 & $1.86 E-03$ & 44.21 & 5.63 & $2.88 E-03$ & 43.26 & 6.52 & $3.49 E-03$ \\
\hline $\mathrm{C} w-55-100$ & 37.40 & 3.62 & $2.59 E-03$ & 42.49 & 6.01 & $3.33 E-03$ & 39.18 & 6.40 & $4.17 E-03$ \\
\hline
\end{tabular}

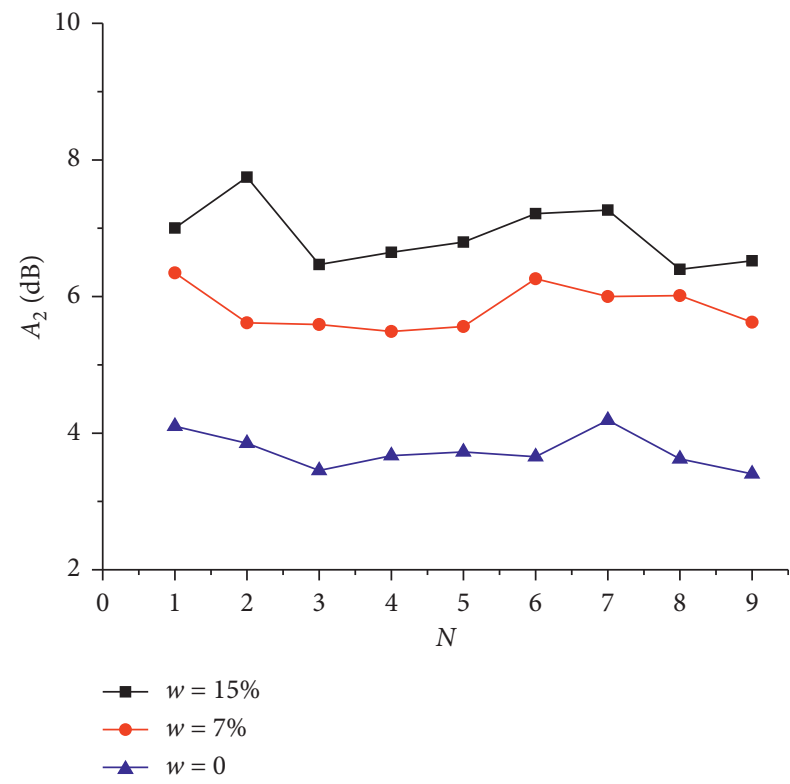

Figure 7: The effect of corrosion rate on the value of $A_{2}$.

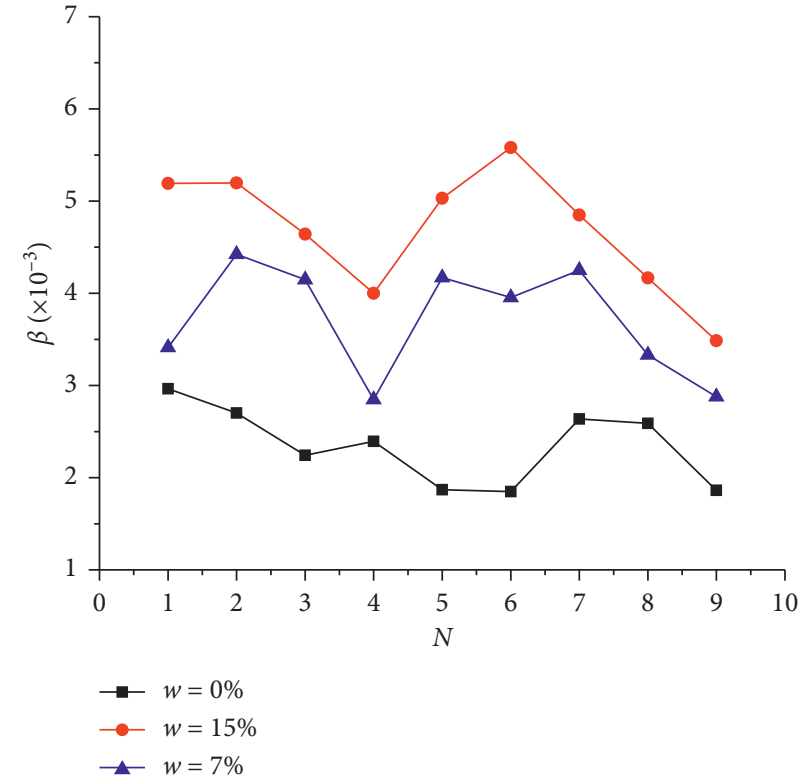

Figure 8: The effect of corrosion rate on the value of $\beta$. 
4.2. Analysis of the Relation between Nonlinear Coefficient and Ultimate Bonding Strength. Based on the concept of damage mechanics, the relation between the nonlinear coefficient and damage variable can be derived from combining the Loland damage model with nonlinear coefficient, as follows:

$$
\beta=\frac{D}{\varepsilon}
$$

where $D$ is the damage variable and $\varepsilon$ is the material strain. $\beta$ represents the growth rate of damage variable with strain. Utilizing the nonlinear coefficient, it is accessible to evaluate the effect of different corrosion on the changing damage trend of the specimen. From equation (15), there is a positive correlation between the nonlinear coefficient and damage variable. Therefore, when the material strain is identified, the coefficient $\beta$ can well reflect the damage of the specimen. Table 8 shows the fitting equations of ultimate bonding strength with $\beta$.

In addition, the relation between the ultimate bonding strength and the nonlinear coefficient could be expressed as a unified formula, which is equation (16). The fitting formula is also divided into two parts. The slope is the effect of damage on the ultimate bonding strength, and the intercept is the ultimate bonding strength of the RC specimens.

$$
\tau_{u}=k \cdot \beta+\tau_{0},
$$

where $k$ is affected by corrosion rate $(w)$, concrete cover thickness $(c)$, and stirrup spacing $(s)$; $\tau_{0}$ is the ultimate bonding strength of RC specimen. The value of $k$ and $\tau_{0}$ is shown in Table 9, respectively.

4.3. The Effect of Damage on Nonlinear Ultrasonic Characteristic under Step Loading. In order to evaluate the damage degree of the bond performance between reinforcement and concrete caused by the slip of the reinforcement and predict the development of the RC specimens' damage under the pullout force, the ultrasonic scanner was applied to carry out the damage tests each $30 \mathrm{kN}$ until reaching the ultimate pullout capacity of RC specimens. Figure 9(a) shows the changing trend of the nonlinear coefficient of $\mathrm{RC}$ specimens without corrosion during the whole loading process. The nonlinear coefficient gradually keeps rising with the increase in pullout force. When the specimen is subjected to pullout force, bonding stress is generated in the contact surface of reinforcement and concrete and rises until the generation of shear cracks with the increasing load. Then, the damage of RC specimens becomes extensive with the development of cracks. When the load reaches the specimen's ultimate capacity, the splitting failure of concrete could be observed. Meanwhile, the nonlinear coefficient characterizing the damage degree of RC specimens also gradually increases with the exacerbation of damage, which is consistent with actual experimental data. Figures 9(b) and 9(c) show the change in trend of the nonlinear coefficient with different corrosion rates. Through comparing these three graphs, some phenomena can be revealed, as follows.
TABle 8: The expression of the ultimate bonding strength and nonlinear coefficient $\beta$.

\begin{tabular}{lcc}
\hline Specimen & \multicolumn{2}{c}{$\tau_{u}=a_{u} \cdot \beta+b_{u}$} \\
& $a_{u}$ & $b_{u}$ \\
\hline $\mathrm{C} w-35-0$ & -715.12 & 11.22 \\
$\mathrm{C} w-35-150$ & -735.48 & 11.48 \\
$\mathrm{C} w-35-100$ & -838.50 & 12.23 \\
$\mathrm{C} w-45-0$ & -1237.46 & 12.96 \\
$\mathrm{C} w-45-150$ & -1237.46 & 12.96 \\
$\mathrm{C} w-45-100$ & -476.73 & 11.74 \\
$\mathrm{C} w-55-0$ & -1056 & 14.83 \\
$\mathrm{C} w-55-150$ & -1319.5 & 14.79 \\
$\mathrm{C} w-55-100$ & -948.95 & 15.11 \\
\hline
\end{tabular}

TABle 9: The range of the coefficient in equation (16).

\begin{tabular}{lccc}
\hline $\begin{array}{l}\text { Concrete cover } \\
\text { thickness }\end{array}$ & $c=35 \mathrm{~mm}$ & $c=45 \mathrm{~mm}$ & $c=55 \mathrm{~mm}$ \\
\hline$k$ & $-838 \leq k \leq-715$ & -1237 & $-1319 \leq k \leq-948$ \\
$\tau_{0}(\mathrm{MPa})$ & 11.64 & 12.55 & 14.91 \\
\hline
\end{tabular}

When the RC specimen is not subjected to load, the nonlinear coefficient $\beta$ is not 0 , indicating that the specimen shows some nonlinear features in the initial state for the discreteness of the concrete. Besides, the nonlinear coefficients of corroded specimens are larger than those of noncorroded specimens, showing that corrosion has a great influence on the damage of RC specimens. Also, at the same load condition, the higher the corrosion rate of reinforcement is, the greater the nonlinear coefficient of the specimen would be.

Through comparing the change in trend of the nonlinear coefficient of specimens with the same corrosion rate, the damage degree of specimens decreases gradually with the enhancement of stirrup ratio under the same load, indicating circumferential restraint of stirrups effectively retards the development of cracks resulting from the slip of reinforcement during the loading process. In addition, there is a negative correlation between the concrete cover thickness and the damage degree of the specimen, indicating that adding the concrete cover thickness could elevate the pullout resistance and delay the damage of the specimen.

During the initial loading period, the nonlinear coefficient shows a great fluctuation and discreteness for the $\mathrm{RC}$ specimens with different corrosion rates. Corrosion plays a significant role in controlling the damage of RC specimens at this stage. With the increase in test load, the pullout force dominates the damage of RC specimens, resulting in regular change of the nonlinear coefficient under the same.

4.4. Sensitivity Analysis of Tested Damage Parameters. The nonlinear coefficient and the acoustic parameter of RC specimens are compared to investigate the sensitivity of these two parameters to the damage of $\mathrm{RC}$ specimens. Taking the value of parameters at $0 \mathrm{kN}$ as reference, the 


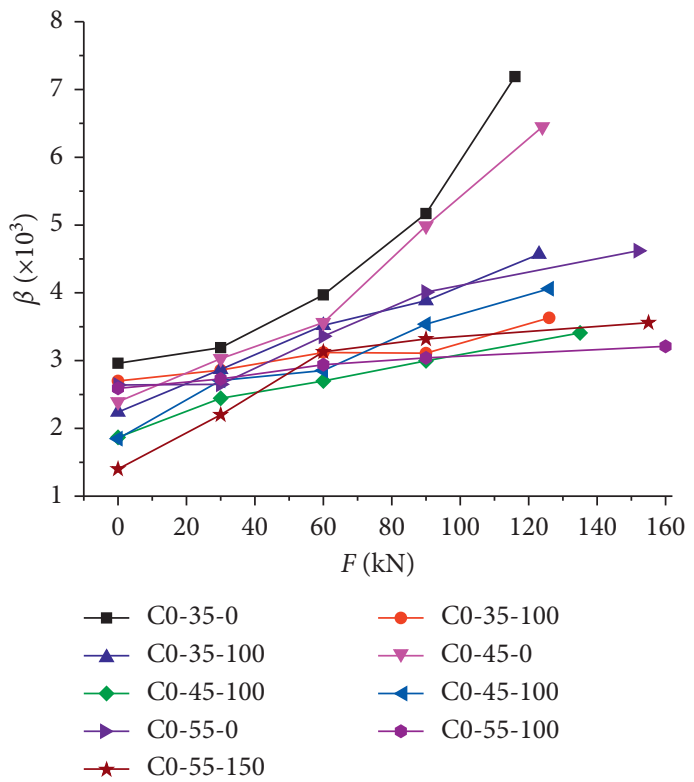

(a)

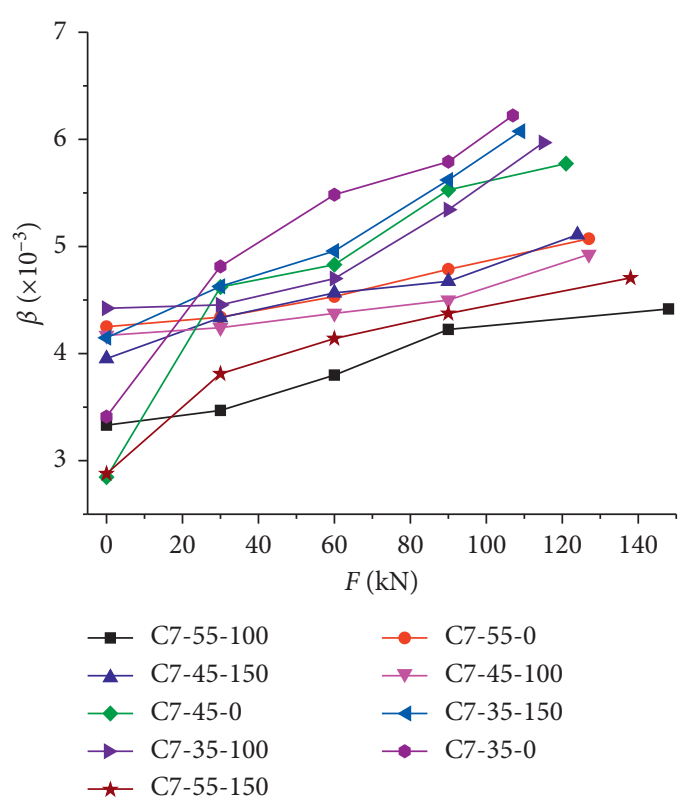

(b)

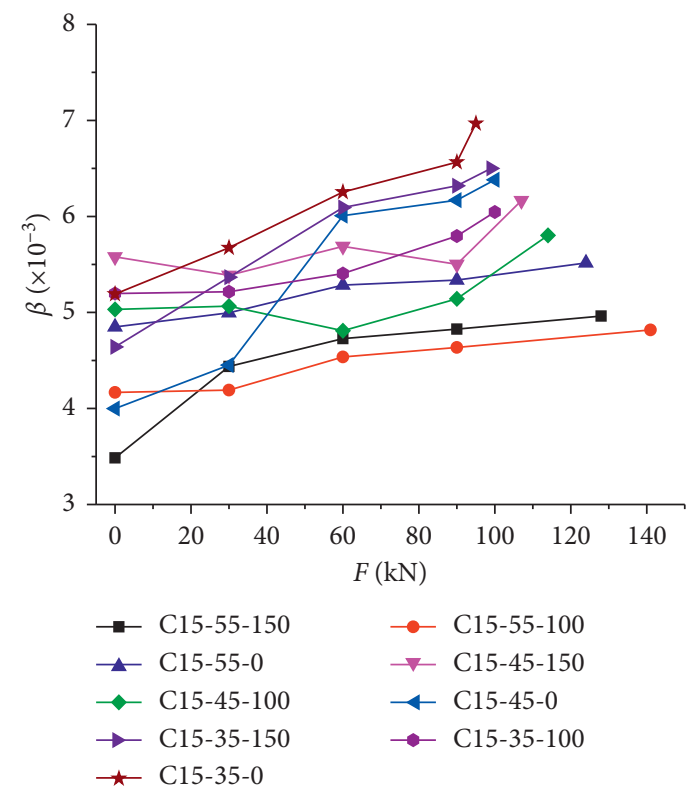

(c)

Figure 9: The changing trend of specimens' nonlinear coefficient with putout load (a) for the specimens without corrosion; (b) for the specimens with $7 \%$ corrosion rate; and (c) for the specimens with $15 \%$ corrosion rate.

relative nonlinear coefficient and relative ultrasonic velocity at $30 \mathrm{kN}, 60 \mathrm{kN}, 90 \mathrm{kN}$, and ultimate load could be determined, respectively. The calculation results of respective specimen are shown in Figure 10. In addition, the maximum differences $\left(\Delta n_{\max }, \Delta v_{\max }\right)$ of the relative nonlinear coefficient and relative ultrasonic velocity are listed in Table 10. Also, the sensitivity of these two parameters to the damage of RC specimens could be evaluated through the value of $\Delta n_{\max } / \Delta v_{\max }$.

Due to the sustainable development of cracks in specimens with increasing load, the internal damage of specimens is also aggravating. Therefore, the ultrasound in the sample velocity is in the downward trend with the increase of specimen's defects while the nonlinear coefficient increases dramatically, as shown in Figure 10. Moreover, the change range of ultrasonic velocity from 0 to ultimate load is far less than that of the nonlinear coefficient. From Table 10, the value of $\Delta n_{\max }$ is much larger than that of $\Delta v_{\max }$ and the value of $\Delta n_{\max } / \Delta v_{\max }$ could reach a maximum of 21 according to the measured data, indicating the nonlinear coefficient is more sensitive than that of ultrasonic velocity. Therefore, it is appropriate to apply the nonlinear coefficient to evaluate the damage degree of the specimen. 

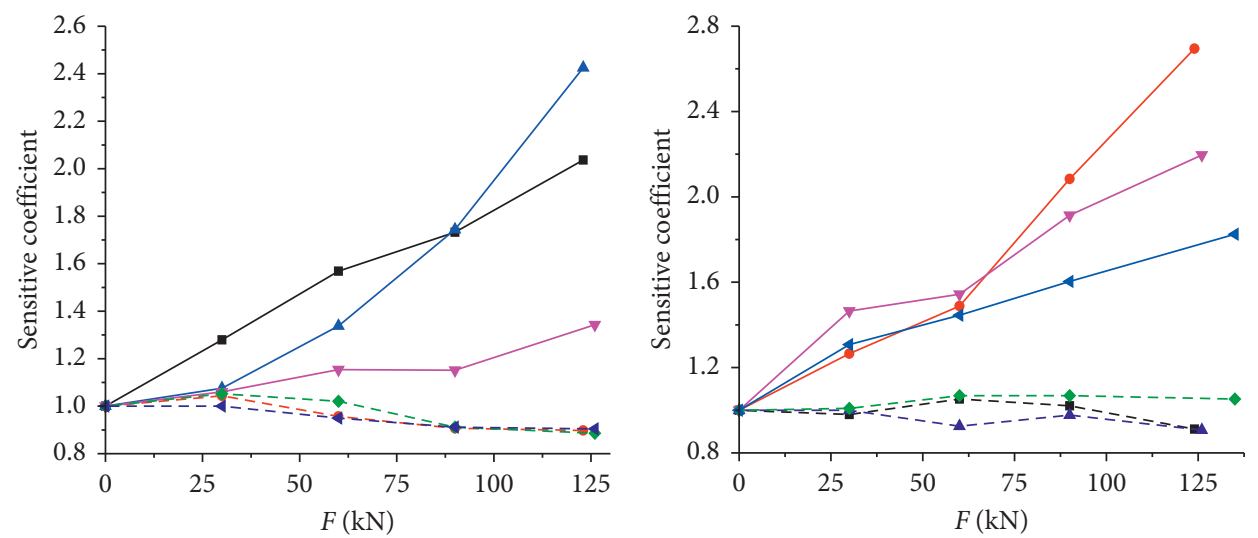

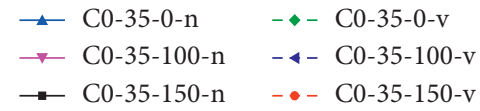

(a)

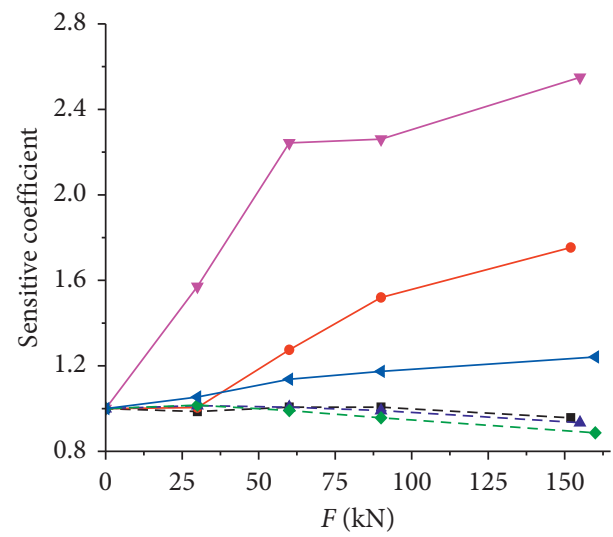

$\rightarrow \mathrm{C} 0-55-150-\mathrm{n} \quad-\mathrm{C} 0-55-0-\mathrm{v}$

- C C $-55-100-\mathrm{v} \quad$ - - C0-55-150-v

(c)

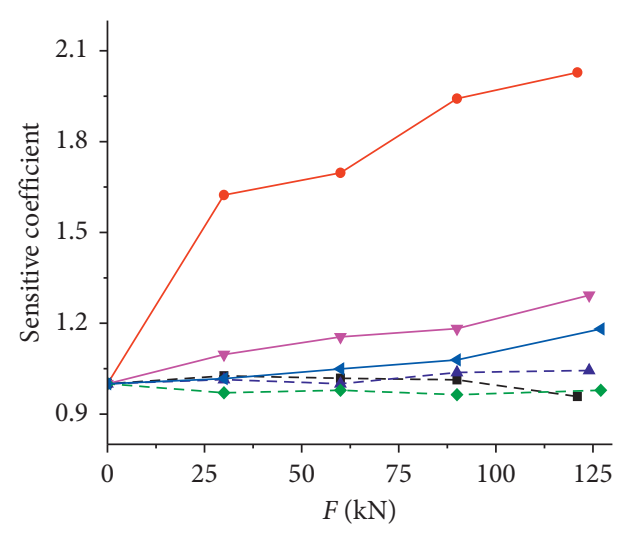

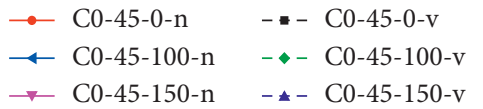

(b)

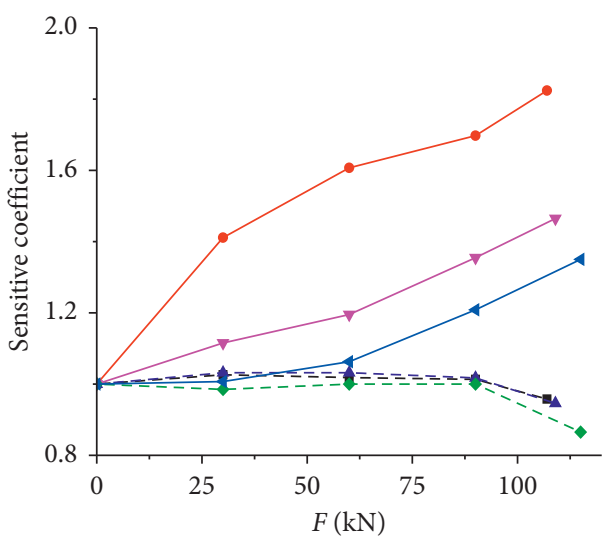

$\rightarrow$ C7-35-0-n $\longleftarrow$ C7-35-100-n

$\rightarrow \mathrm{C} 7-35-150-\mathrm{n} \quad-\mathrm{C} 7-35-0-\mathrm{v}$

- - C7-35-100-v - - C7-35-150-v

(d)

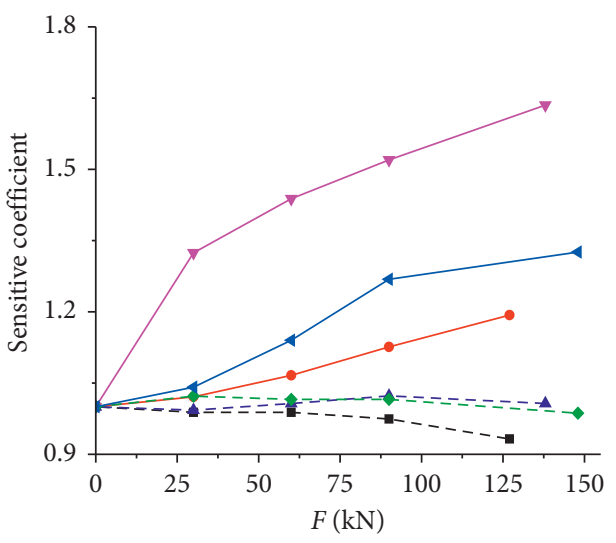

$$
\begin{aligned}
& \text {-C7-55-0-n - - C7-55-0-v } \\
& \longleftarrow \text { C7-55-100-n }- \text { C7-55-100-v } \\
& \rightarrow \text { C7-55-150-n - - C7-55-150-v }
\end{aligned}
$$

(f)

(e)

FIgURE 10: Continued. 


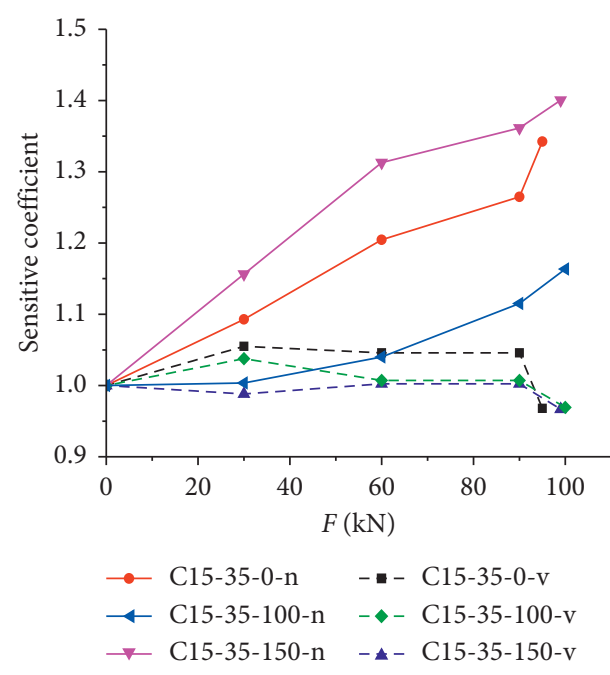

(g)

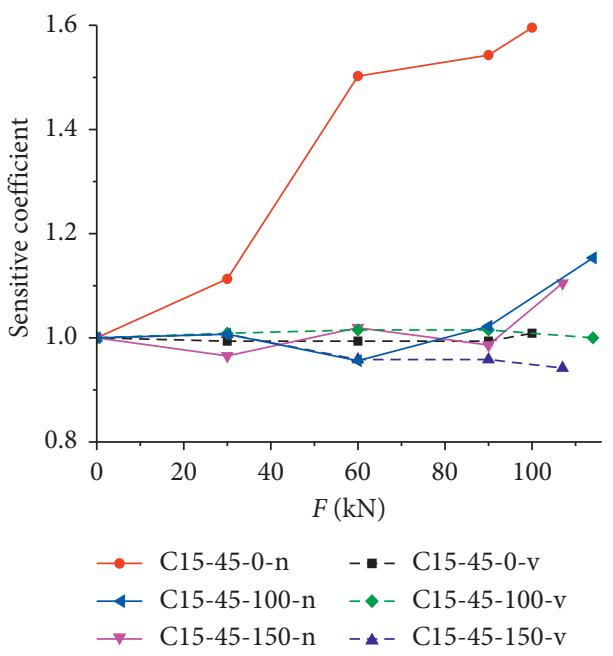

(h)

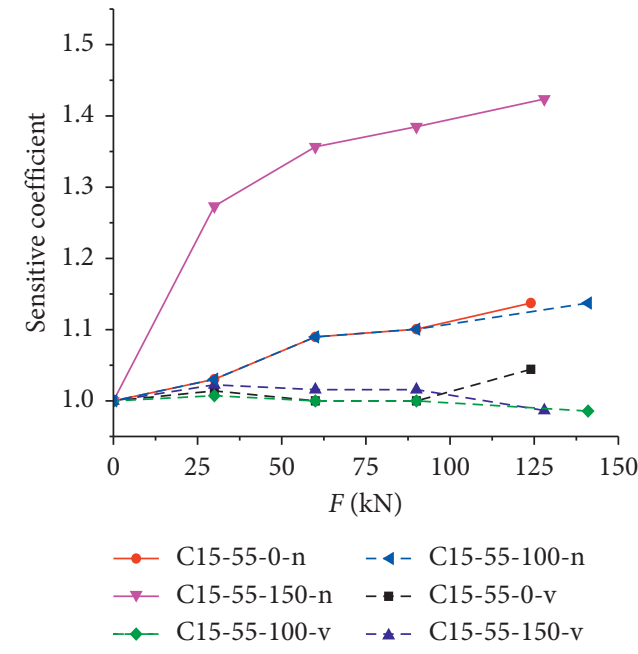

(i)

FIGURE 10: The change in trend of the relative nonlinear coefficient and relative ultrasonic velocity of specimens: (a) C0-35-s group; (b) C045-s group; (c) C0-55-s group; (d) C7-35-s group; (e) C7-45-s group; (f) C7-55-s group; (g) C15-35-s group; (h) C15-45- $s$ group; and (i) C15$55-s$ group.

TABLE 10: The analysis of the relative nonlinear coefficient and relative ultrasonic velocity.

\begin{tabular}{lccc}
\hline Specimen & $\Delta n_{\max }$ & $\Delta v_{\max }$ & $\Delta n_{\max } / \Delta v_{\max }$ \\
\hline C0-35-s & 1.47 & 0.11 & 13.36 \\
C0-45-s & 1.70 & 0.09 & 18.89 \\
C0-55-s & 1.55 & 0.11 & 14.09 \\
C7-35-s & 0.82 & 0.14 & 5.86 \\
C7-45-s & 1.02 & 0.14 & 7.28 \\
C7-55-s & 0.63 & 0.07 & 9.0 \\
C15-35-s & 0.4 & 0.04 & 10.0 \\
C15-45-s & 0.6 & 0.06 & 10.0 \\
C15-55-s & 0.42 & 0.02 & 21 \\
\hline
\end{tabular}

\section{Conclusions}

A series of experiments was carried out to investigate the effects of stirrup spacing, concrete cover thickness, and corrosion rate on the bond performance between reinforcement and concrete. The empirical equations of the bond-slip relation model were established to describe the $\mathrm{RC}$ specimens' bond performance. The ultrasonic technology was applied to detect the damage of RC specimens. Based on the test results, the main conclusions are as follows:

(1) Based on the fitting bonding strength formula and slip formula, it is possible to predict the bond strength and slip between longitudinal reinforcement and concrete when the corrosion level, concrete cover thickness, and stirrup ratio of RC specimen are given. In addition, the concrete cover thickness and stirrup ratio are positively correlated to the bond performance of RC specimens, while corrosion rate varies inversely with that of RC specimens. 
(2) The bond-slip relation model with four stages was established to describe the bond performance of RC specimens according to the experimental data. Then, the corresponding fitting formula of each stage was provided to evaluate the bond performance between longitudinal reinforcement and concrete. Also, the predicted results were compared with the actual tested data, presenting outstanding accuracy and stability.

(3) The ultrasonic technology was used to detect the damage of RC specimens, and the nonlinear coefficient was proposed to characterize the damage degree of RC specimens. Meanwhile, the relationship between the nonlinear coefficient and corrosion rate was determined, and the empirical equation of ultimate bonding strength with the nonlinear coefficient was also established. Comparing the sensitiveness of ultrasonic velocity to the damage of RC specimens, the nonlinear coefficient was considered more appropriate to detect the degree of damage.

The effects of three experimental parameters on the bond performance between longitudinal reinforcement and concrete were investigated in this paper, which may provide specific guidance for evaluating the bond performance of existing RC structures. The detection method using ultrasonic technology also contributes to the evaluation of the damage degree of RC structures. In addition, the tested data of this study are general and may be used directly and as a guide for further studies.

\section{Data Availability}

The data used to support the findings of this study are available from the corresponding author upon request.

\section{Conflicts of Interest}

The authors declare that there are no conflicts of interest regarding the publication of this paper.

\section{Acknowledgments}

This work was financially supported by the National Natural Science Foundation of China (Grant no. 51608069). The authors would like to express their gratitude to Qingcheng Mo and Jiyang Shen for carrying out the excellent experiment of corroded RC specimens and giving the complete experimental data. The authors would also like to thank the members of the HIT 504 office for their selfless help and useful suggestions.

\section{References}

[1] A. Hamid, "Improving structural concrete durability in the Arabian gulf," Concrete International, vol. 17, no. 7, pp. 32-35, 1995.

[2] P. F. Marques and A. Costa, "Service life of RC structures: carbonation induced corrosion. Prescriptive vs. performance-based methodologies," Construction and Building Materials, vol. 24, no. 3, pp. 258-265, 2010.

[3] A. A. Almusallam, A. S. Al-Gahtani, A. R. Aziz et al., "Effect of degree of corrosion on the properties of reinforcing steel bars," Construction and Building Materials, vol. 15, no. 8, pp. 361-368, 2001.

[4] A. A. Almusallam, A. S. Al-Gahtani, A. R. Aziz, and Rasheeduzzafar, "Effect of reinforcement corrosion on bond strength," Construction and Building Materials, vol. 15, no. 8, pp. 361-368, 2001.

[5] X. Du, L. Jin, and R. Zhang, "Modeling the cracking of cover concrete due to non-uniform corrosion of reinforcement," Corrosion Science, vol. 89, pp. 189-202, 2014.

[6] K. Bhargava, A. K. Ghosh, Y. Mori, and S. Ramanujam, "Model for cover cracking due to rebar corrosion in RC structures," Engineering Structures, vol. 28, no. 8, pp. 10931109, 2006.

[7] H. Zhou, J. Lu, X. Xv, B. Dong, and F. Xing, "Effects of stirrup corrosion on bond-slip performance of reinforcing steel in concrete: an experimental study," Construction and Building Materials, vol. 93, pp. 257-266, 2015.

[8] M. G. Stewart, "Mechanical behaviour of pitting corrosion of flexural and shear reinforcement and its effect on structural reliability of corroding RC beams," Structural Safety, vol. 31, no. 1, pp. 19-30, 2009.

[9] Q. Suo and M. G. Stewart, "Corrosion cracking prediction updating of deteriorating RC structures using inspection information," Reliability Engineering \& System Safety, vol. 94, no. 8, pp. 1340-1348, 2009.

[10] C. Fang, K. Lundgren, L. Chen, and C. Zhu, "Corrosion influence on bond in reinforced concrete," Cement and Concrete Research, vol. 34, no. 11, pp. 2159-2167, 2004.

[11] R. François and G. Arliguie, "Effect of microcracking and cracking on the development of corrosion in reinforced concrete members," Magazine of Concrete Research, vol. 51, no. 2, pp. 143-150, 1999.

[12] A. A. Torres-Acosta, S. Navarro-Gutierrez, and J. TeránGuillén, "Residual flexure capacity of corroded reinforced concrete beams," Engineering Structures, vol. 29, no. 6, pp. 1145-1152, 2007.

[13] D. V. Val, "Deterioration of strength of RC beams due to corrosion and its influence on beam reliability," Journal of Structural Engineering, vol. 133, no. 9, pp. 1297-1306, 2007.

[14] D. V. Val and L. Chernin, "Serviceability reliability of reinforced concrete beams with corroded reinforcement," Journal of Structural Engineering, vol. 135, no. 8, pp. 896-905, 2009.

[15] G. Campione, F. Cannella, and L. Cavaleri, "Shear and flexural strength prediction of corroded R.C. beams," Construction and Building Materials, vol. 149, no. 15, pp. 395-405, 2017.

[16] G. Campione and F. Cannella, "Engineering failure analysis of corroded RC beams in flexure and shear," Engineering Failure Analysis, vol. 86, pp. 100-114, 2018.

[17] J. Rodriguez, L. Ortega, and J. Casal, "Load carrying capacity of concrete structures with corroded reinforcement," Construction and Building Materials, vol. 11, no. 4, pp. 239-248, 1997.

[18] H. S. Lee, T. Noguchi, and F. Tomosawa, "Evaluation of the bond properties between concrete and reinforcement as a function of the degree of reinforcement corrosion," Cement \& Concrete Research, vol. 32, no. 8, pp. 1313-1318, 2002.

[19] M. Davis, N. A. Hoult, and A. Scott, "Distributed strain sensing to determine the impact of corrosion on bond performance in reinforced concrete," Construction and Building Materials, vol. 114, pp. 481-491, 2016. 
[20] F. Tondolo, "Bond behaviour with reinforcement corrosion," Construction and Building Materials, vol. 93, pp. 926-932, 2015.

[21] K. Bhargava, A. K. Ghosh, Y. Mori, and S. Ramanujam, "Corrosion-induced bond strength degradation in reinforced concrete-analytical and empirical models," Nuclear Engineering and Design, vol. 237, no. 11, pp. 1140-1157, 2007.

[22] Y. Auyeung, P. Balaguru, and L. Chung, "Bond behavior of corroded reinforcement bars," ACI Materials Journal, vol. 97, no. 2, pp. 214-220, 2000.

[23] W. Yeih and R. Huang, "Detection of the corrosion damage in reinforced concrete members by ultrasonic testing," Cement and Concrete Research, vol. 28, no. 7, pp. 1071-1083, 1998.

[24] M.-T. Liang and P.-J. Su, "Detection of the corrosion damage of rebar in concrete using impact-echo method," Cement and Concrete Research, vol. 31, no. 10, pp. 1427-1436, 2001.

[25] T. Watanabe, H. T. H. Trang, K. Harada, and C. Hashimoto, "Evaluation of corrosion-induced crack and rebar corrosion by ultrasonic testing," Construction and Building Materials, vol. 67, pp. 197-201, 2014.

[26] R. Capozucca, "Detection of damage due to corrosion in prestressed RC beams by static and dynamic tests," Construction and Building Materials, vol. 22, no. 5, pp. 738-746, 2008.

[27] C. Andrade and C. Alonso, "Corrosion rate monitoring in the laboratory and on-site," Construction and Building Materials, vol. 10, no. 5, pp. 315-328, 1996.

[28] D. Coronelli and P. Gambarova, "Structural assessment of corroded reinforced concrete beams: modeling guidelines," Journal of Structural Engineering, vol. 130, no. 8, pp. 12141224, 2004

[29] G. Mancini and F. Tondolo, "Effect of bond degradation due to corrosion-a literature survey," Structural Concrete, vol. 15, no. 3, pp. 408-418, 2014. 